\title{
Net-Shape Manufacturing using Hybrid Selective Laser Melting/Hot Isostatic Pressing
}

Hany Hassanin ${ }^{1}$, Khamis Essa ${ }^{2}$, Chunlei Qiu ${ }^{2}$, Ali M. Abdelhafeez ${ }^{2}$, Nicholas J.E. Adkins ${ }^{3}$, Moataz M. Attallah ${ }^{3}$

1School of Mechanical and Automotive Engineering, Kingston University, London SW15 3DW, UK 2School of Mechanical Engineering, The University of Birmingham, Edgbaston B15 2TT, UK 3School of Metallurgy and Materials, The University of Birmingham, Edgbaston B15 2TT, UK 


\begin{abstract}
Purpose: A manufacturing technology using hybrid Selective Laser Melting / Hot Isostatic Pressing (SLM/HIP) process has been developed to produce full density net-shape components more rapidly and at lower cost than processing by SLM alone.
\end{abstract}

Design/methodology/approach: Ti-6Al-4V powder was encapsulated in-situ by the production of as-SLMed shell prior to the HIP process. After HIPping, the SLM shell is an integral part of the final component. Finite element modelling (FE) based on pure plasticity theory of porous metal coupled with an iterative procedure has been adopted to simulate HIPping of the encapsulated Ti-6Al-4V powder and SLMed shell. Two demonstrator parts have been modelled, designed, produced and experimentally validated. Geometrical analysis and microstructural characterisation have been carried out to demonstrate the efficiency of the process.

Findings: the FE model is in agreement with the measured data obtained and confirms that the design of the shell affects the resulting deformed parts. In addition, the SEM and EBSD of the interior and exterior parts reveal a considerably different grain structure and crystallographic orientation with a good bonding between the SLMed shell and HIPped powder.

Originality/value: An approach to improve SLM productivity by combining it with HIP is developed to further innovate the advanced manufacturing field. The possibility of the hybrid SLS/HIP supported by FEA simulation as a net shape manufacturing process for fabrication of high performance parts has been demonstrated

Keywords: Hot Isostatic Pressing; Selective Laser Melting; Finite element modelling; Powder Consolidation 


\section{Introduction}

SLM is one of the additive manufacturing technologies (AM) that can produce 3D components with almost no geometrical restrictions. The build rate during the melting process is a function of layer thickness, laser process parameters and laser scanned area. A drawback of SLM process is its slow build rate when compared to other manufacturing technologies. More than $80 \%$ of the total SLM time is consumed during the laser scanning process when building large volume components. Buchbinder et al. have been able to produce high quality aluminium alloy with high build rate using a $1 \mathrm{~kW}$ laser beam and a multi-beam system (Buchbinder et al., 2011). Spiral growth manufacturing (SGM) is another powder bed SLM technique developed by Liverpool University to improve build performance (Hauser et al., 2005). The influence of laser process parameters and the build direction on the microstructure and the density of the SLM parts have been investigated by many workers. Parts made by SLM, show microstructural and mechanical properties different from those found in conventionally manufactured parts (Read et al., 2015, Qiu et al., 2015, Mumtaz and Hopkinson, 2009, Wong et al., 2007, Mumtaz and Hopkinson, 2010, Chantarapanich et al., 2014, Simhambhatla and Karunakaran, 2015, Li et al., 2016).

Hot Isostatic Pressing (HIP) is one of the processes that is used as a post-processing tool to improve these properties (Ma et al., 2014, Khor and Gu, 1998). The process of hot isostatic pressing (HIP) is a popular manufacturing route used for producing parts from high performance powder which are difficult to machine. The shape of the consolidated powder is different from the original one due to the consolidation of the powder (Dong et al., 1996, Häggblad and Li, 1995). Shima et al. proposed a plasticity theory for porous metals (Shima and Oyane, 1976). In 1980, Cassenti was the first to initiate a study of modelling the HIPping process using an elasto-plastic large-deformation model with implicit thermal calculations (Cassenti, 1980). Some developments are then included in the work of Abouaf and Nohara 
(Abouaf, 1985, Khoei et al., 2013, Abouaf et al., 1982, Jinka and Lewis, 1994, Abouaf et al., 1988). Through these developments, the constitutive equation is adapted to account for elasticity, visco-plasticity, and thermal effects, to model the mechanical behaviour of the powder. Similar FE models are also developed by Svoboda and Wikman who developed a finite element simulation of hot isostatic pressing using a combined material model (Wikman et al., 2000). The constitutive equations of this model account for both granular and viscoplastic behaviour. The granular plasticity model is used for the early stage of the consolidation and a viscoplastic model is for intermediate and later stages. Gillia et al. proposed a viscoplastic model which takes into account the strain hardening effect of the powder material (Gillia et al., 2007). Yuan et al. constructed an FE model to predict the final dimensions of shaped part produced by HIPping Ti-6Al-4V powder (Yuan et al., 2007). They used the constitutive equations for plastic yield. Constitutive models that describe other densification mechanisms were not taken into account. This was justified based on the fact that more than $90 \%$ of powder density is gained within this instantaneous plastic yield mechanism which has relative concise formulation with fewer parameters involved. Furthermore, Das et al. (Das et al., 1999), combined the benefits of both selective laser sintering (SLS) and Hot isostatic pressing (HIP) to manufacture net shape parts. In Das et al's research (Das et al., 1999), they focused on the microstructural study of the parts. No work on the geometrical changes or parts design of the process was made.

In this work, a shell or a skin of the metal part is built by SLM while the interior of the part is left in its powder form without laser scanning to speed up the manufacturing process. The resultant encapsulated HIP capsule is de-gassed, sealed and HIPped to achieve a full density part. The final shape of the HIPped sample is measured using a laser 3D scanner. The measurements were compared with the predicted FEA results. To ensure the structure integrity, the interface between the SLM shell and the interior HIPped powder has been 
characterised using SEM and EBSD is used to characterize the crystalline phases and their orientations of both the shell and HIPped structures.

\section{Experimental}

Gas atomised Ti-6Al-4V powder supplied by TLS Technik GmbH in the size range of 2550 $\mu$ m was used. A Concept Laser M2 Cusing SLM system which employs an Nd:YAG laser with a wavelength of $1075 \mathrm{~nm}$ and a constant beam spot size of $50 \mu \mathrm{m}$ with a melt pool of approximately of $150 \mu \mathrm{m}$ in diameter and a maximum laser output power of $400 \mathrm{~W}$ and a maximum laser scanning speed of $7000 \mathrm{~mm} / \mathrm{s}$ has been used to prepare the in-situ shelling demonstrator parts. The demonstrator parts shells were fabricated at a laser power of 200W and a laser scanning speed of $1300 \mathrm{~mm} / \mathrm{s}$. Next, the as-fabricated SLM parts filled with the powder during the SLM process were then inspected against leaking using helium leaking test. Afterwards, the developed demonstrator parts were degassed, sealed and HIPped. The degassing process was conducted in a vacuum at room temperature for 24 hours to remove entrapped gases. Once the degassing was completed, the demonstrator parts were then crimp sealed under vacuum conditions and welded. In the HIP process the pressure and temperature loading was applied to all the free edges of the capsule elements. The heating rate is $5^{\circ} \mathrm{C} / \mathrm{min}$ up to $920^{\circ} \mathrm{C}$ and a pressure of $100 \mathrm{MPa}$ with a dwell time of 4 hours and then cooling down with rate equivalent to heating up rate. The manufacturing processes comprise shell design fabrication using SLM followed by realisation of the target geometry after HIPping.

Several mechanisms are involved in powder densification however plastic collapse, which has relatively a concise formulation with fewer controlling parameters, account for more than 90\% of powder final density (Gillia et al., 2007). In this investigation, a modified Gurson's porous metal plasticity model; depicted in Equation (1); has been used which defines the 
inelastic flow of the powder as a continuum material with evolving relative density upon loading.

$$
\begin{aligned}
& \phi(\sigma, \rho)=\left(\frac{q}{\sigma_{y}}\right)^{2}+2 q_{1}(1-\rho) \operatorname{Cosh}\left(-q_{2} \frac{3 P}{2 \sigma_{y}}\right)-1\left(q_{3}(1-\rho)\right)^{2}=0 \\
& q=\sqrt{\frac{3}{2} \mathrm{~S}: \mathrm{S}} \\
& P=-\frac{1}{3} \sigma: \mathrm{I}
\end{aligned}
$$

Where $\mathrm{q}$ is effective Von Mises stress, $\mathrm{S}$ is the deviatoric Cauchy stress tensor, $\mathrm{P}$ is the hydrostatic pressure, $\rho$ is the relative density and $\mathrm{q} 1, \mathrm{q} 2$ and $\mathrm{q} 3$ are material parameters. When $\mathrm{q} 1=\mathrm{q} 2=\mathrm{q} 3=1$, Equation (1) reduces to the yield function (Tvergaard, 1981). When q1= $\mathrm{q} 2=\mathrm{q} 3=0$, Equation (1) reduces to the usual Von Mises stress. The elastic modulus and thermal conductivity are dependent on the instantaneous relative density of the powder during the loading cycle as shown in Equation (4) (Gillia et al., 2007) and Equation (5) (Tvergaard, 1981) respectively. The former equation was obtained from testing cold compacted samples at different relative density levels.

$$
\begin{aligned}
& E(\rho, T)=E(1, T)\left(0.1+0.9 \rho^{12}\right) \\
& K_{\text {eff }}=K_{s}\left(\frac{\rho-\rho_{o}}{1-\rho_{o}}\right)^{\frac{3}{2}\left(1-\rho_{o}\right)}
\end{aligned}
$$

Where $E(1, T)$ is the modulus of elasticity at relative density of 1 (no porosity) and temperature (T), $K_{\text {eff }}$ is the effective thermal conductivity, $K_{S}$ is the thermal conductivity of the solid, $\rho_{o}$ is the initial relative density.

SIMULIA Isight was used as an iterative solver that executes ABAQUS CAE and tests the resulting deformed geometry against the targeted one. The iteration procedure starts with axisymmetric FE model of guess shell geometry. The iterative solver then continues to re- 
execute ABAQUS/CAE and change the shell dimensions such as R1 and R2 until the target dimensions of the demonstrator parts, which were first specified in Isight as an objective function are achieved. Figure 1 shows Axial-symmetric FE mesh for two sections representing the solid and hollow cylinder demonstrators while table 1 shows the R1 and R2 iterative values. 


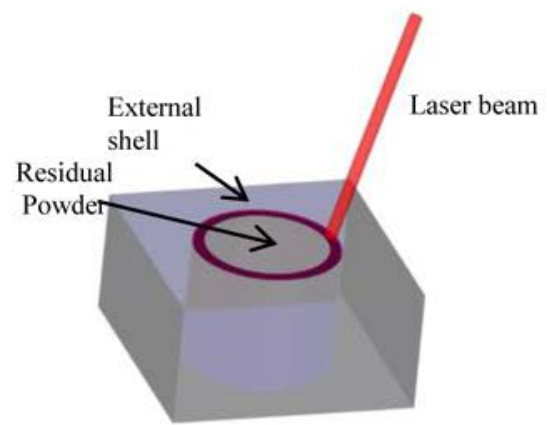

(a)

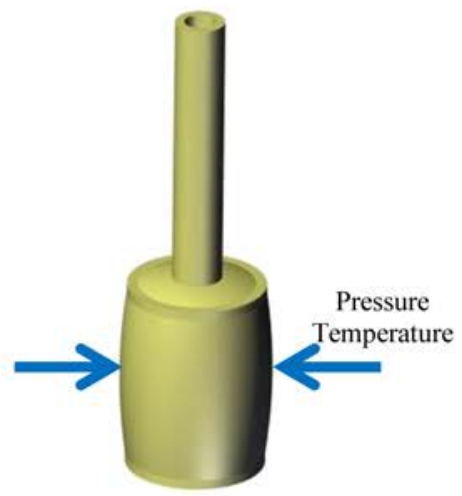

(c)

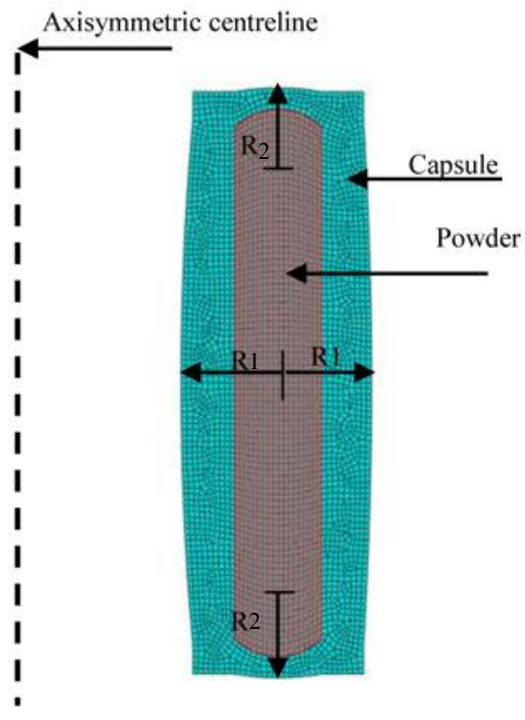

(e)

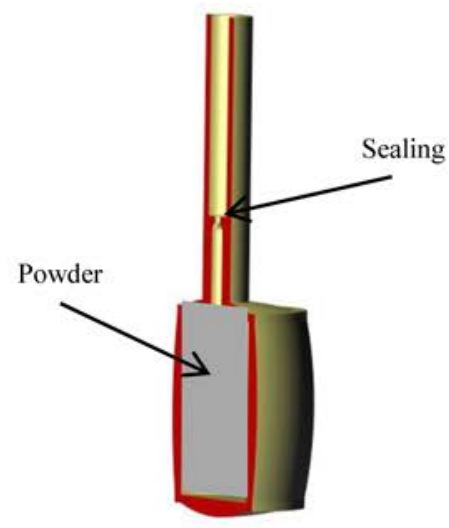

(b)

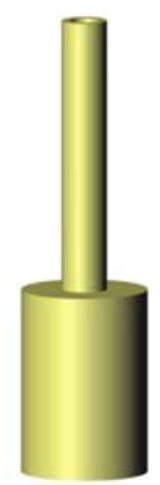

(d)

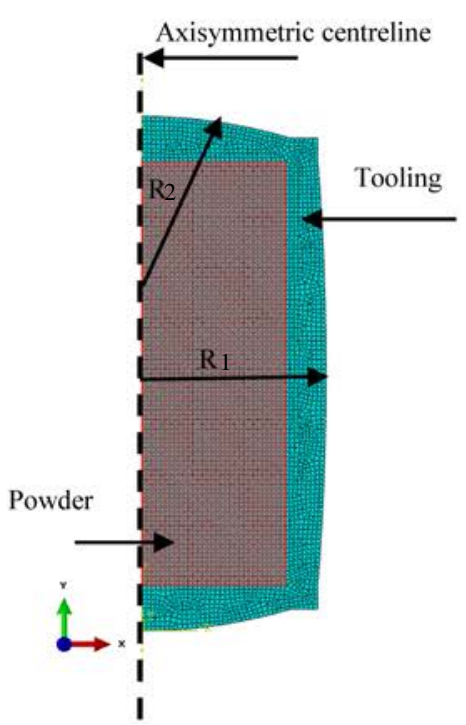

(f)

Figure 1: (a-d), Manufacturing procedure of hybrid SLM/HIP process, (c-d) Axial-symmetric FE mesh for two sections representing the hollow and solid cylinder demonstrators parts with the iterative variables $R_{1}$ and $R_{2}$ (coloured elements represent SLM shell and grey elements represent powders) 
Table 1: Iterative parameters

Parts

Parameters

initial value

Minimum value

Maximum value
Solid cylinder demonstrator

$\mathrm{R}_{1}(\mathrm{~mm})$

100

80

200
$\mathrm{R}_{2}(\mathrm{~mm})$

50

20

100
Hollow cylinder demonstrator

$\mathrm{R}_{1}(\mathrm{~mm}) \quad \mathrm{R}_{2}(\mathrm{~mm})$

$150 \quad 20$

$100 \quad 10$

$300 \quad 50$

\section{Results and Discussion}

The simulation results of the pressure distribution in the consolidated parts, as well as the densification during HIPping are shown in Figure 2. The maximum value of pressure predicted by the simulation is $142 \mathrm{MPa}$, whereas the external pressure load at that time is 100MPa. This increase in the developed pressure can be explained by the difference in the capsule and powder stiffness. The lowest predicted pressure is always located in the powder especially at thick sections. As a consequence of the variation of developed pressure, the relative densities in the powder configurations are also non-uniform. At this stage, the thermal strain effect on the densification can be observed. Large thermal gradient causes a thermal strain in the compacts. Hence, the surface with high temperature is deformed faster than the inner surface and the average relative density of the external parts is higher than the interior especially at regions with low capsule stiffness (high-induced pressure). With the progress of the temperature and pressure, the densification rate has improved significantly. This dramatic improvement is caused by the increasing of the applied and induced pressure. At the end of the HIP cycle, it can be clearly seen that the all the packed powder has been fully densified. 


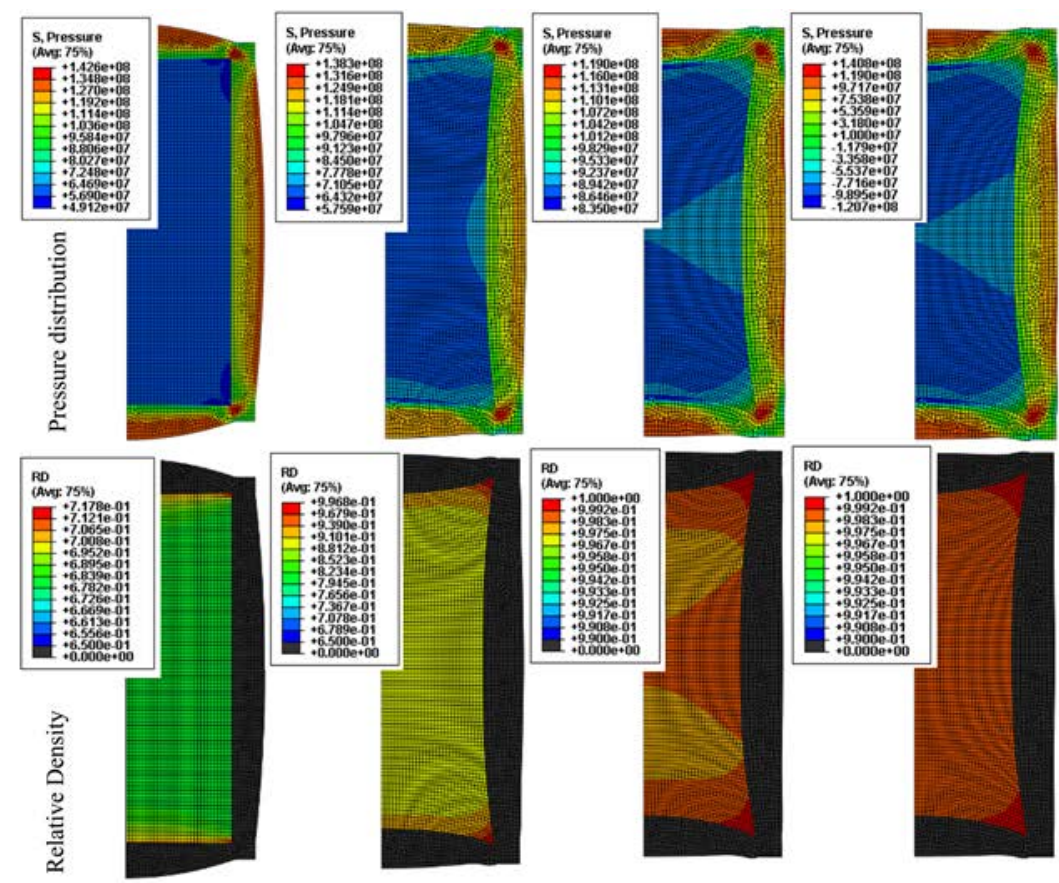

Solid cylinder demonstrator

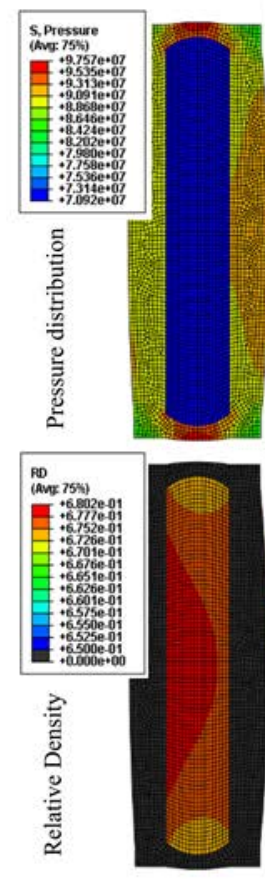

(a)
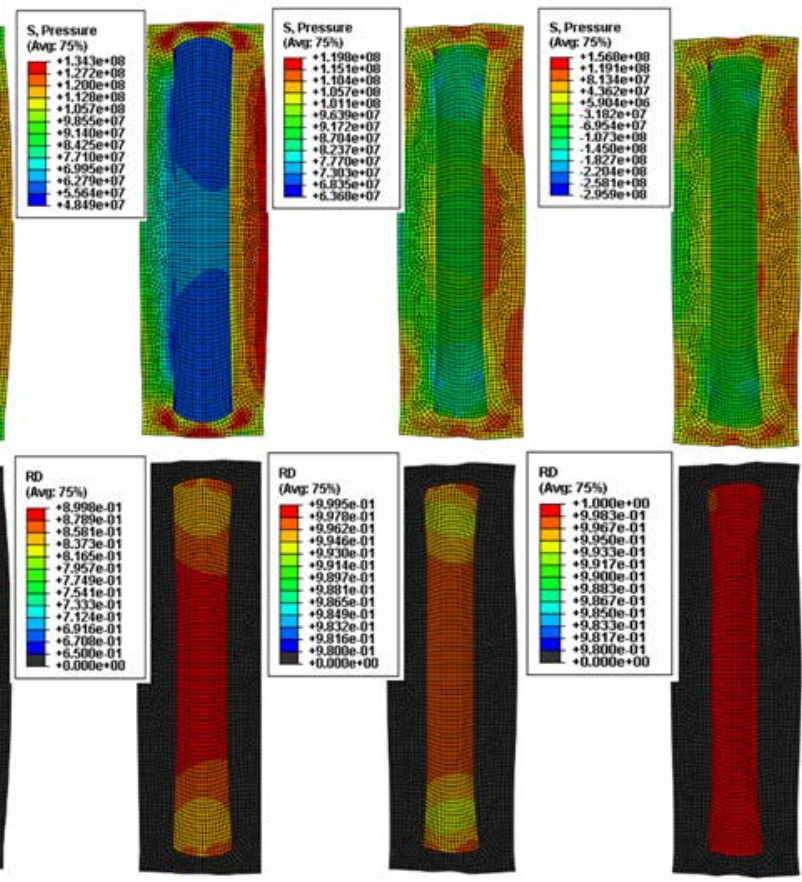

Hollow cylinder demonstrator

(b)

(c)

(d)

Figure 2: Pressure in (Pa) and relative density (RD) distribution during HIPping progress (a) at the beginning of ramping stage, (b) at the middle of the pressure ramp-up stage, (c) At the end of the ramping stage, (d) at the end of the HIP cycle. 
A comparison between the two geometries is illustrated in Figure 3a,b. It can be clearly seen that the predicted simulation results of the two different geometries are in a good agreement with the HIPped demonstrator parts with an accuracy above 98\% confirming that plastic deformation is responsible for the majority of the powder consolidation, during HIPping of Ti-6Al-4V, with the role of creep deformation being minimal. The simulation time of this model is quite fast as compared with other complicated models (Abouaf et al., 1982, Jinka and Lewis, 1994, Abouaf et al., 1988). 
The cross section of the Ti-6Al-4V samples containing the SLMed+HIPed shell and HIPed powder manufactured using SLM/HIP has been characterised and the results are shown in shown in Figure 3c. The images show clearly that there is no boundary or visible gap even after etching, which suggests that sound bonding between the HIPed powder and the shell has been achieved. However, the dissimilarity in microstructure between the HIPed powder and the shell was found to be distinct. The shell is likely to contain well developed basket-weave lamellar microstructure and large columnar grains whereas the as-HIPed powder exhibits a randomly distributed lamellar microstructure and finer equiaxed grains. The columnar grains in the shell show a typical length of more than $1 \mathrm{~mm}$ and a width greater than $100 \mu \mathrm{m}$. On the other hand, the as-HIPped powder has a grain size below $10 \mu \mathrm{m}$, which is consistent with previous study on microstructure of Ti-6Al-4V after SLM (Qiu et al., 2013). The $\alpha$ laths in the SLM-HIPped shells are also longer than laths in the as-HIPped powder. The EBSD analysis results shown in Figure 3d also confirm the distinction in microstructure between SLM/HIPped shells and HIPped powder. The SLM/HIPped shell exhibits strong microtexture with $\alpha$ laths oriented in specified directions. Most of these are oriented along its length (Figure 3d). In addition, strong texture is shown along $<001>$ (Figure 3d), clearly because of the development of columnar prior $\beta$ grains along SLM building direction. Furthermore, the HIPped powder exhibits almost no texture as shown in Figure 3d, which confirms that the grains in HIPped sample are randomly oriented. The presence of dissimilar microstructures within the current hybrid part is believed to show significant influence on its deformation and mechanical properties. Inhomogeneous deformation is expected to happen within the hybrid part under tensile loading. Given that the SLMed+HIPed part shows much coarser grain structure than the simply HIPed powder, the yield strength and ultimate tensile strength of the SLMed+HIPed material is expected to be lower. As a result, plastic deformation would be preferentially concentrated on the side of SLMed+HIPed layer and 
fracture is likely to happen on this side. The HIPed powder is expected to have higher strength and would experience lower deformation than the SLMed+HIPed layer. In addition, the deformation for the HIPed powder would be relatively homogeneous when compared to the SLMed+HIPed layer.

In the proposed technique, a metallic tooling is made by selective laser melting. As such, complex geometries and corresponding modifications in the tooling design can be easily handled. However, the tooling dimensions will be limited to the build envelope of commercial SLM machines, which is typically less than $0.5 \times 0.5 \times 0.5 \mathrm{~m}$. Additionally, if support structures were required while building the tooling with SLM and couldn't be removed, the integrity and microstructure of the fabricated part might be affected. From simulation point of view, the developed model is currently limited to 2D and axisymmetric geometries. If a complex 3D part is required to be fabricated by this approach, the part should be divided first into a number of 2D sections where a FE model is built for each section and the same approach is followed. An assembly of the tooling design from each section will be an additional step. 
(a)

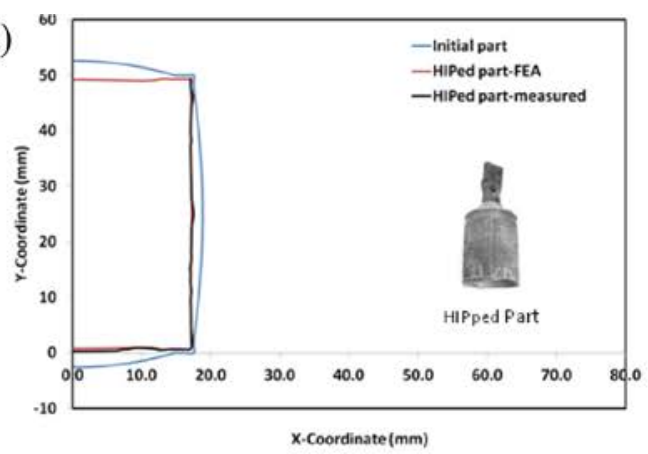

(c)

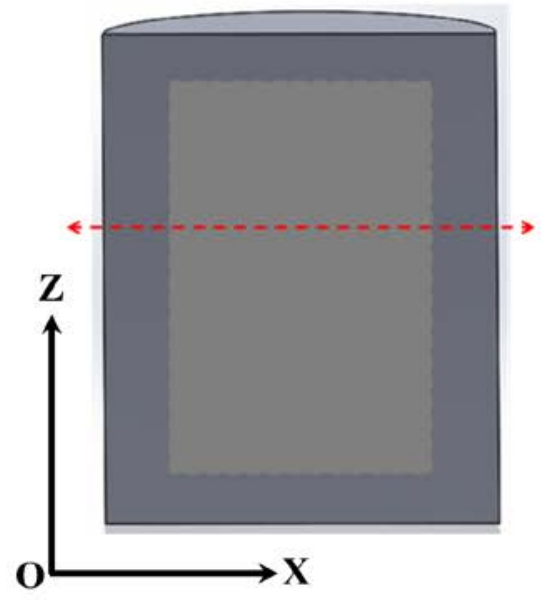

(b)

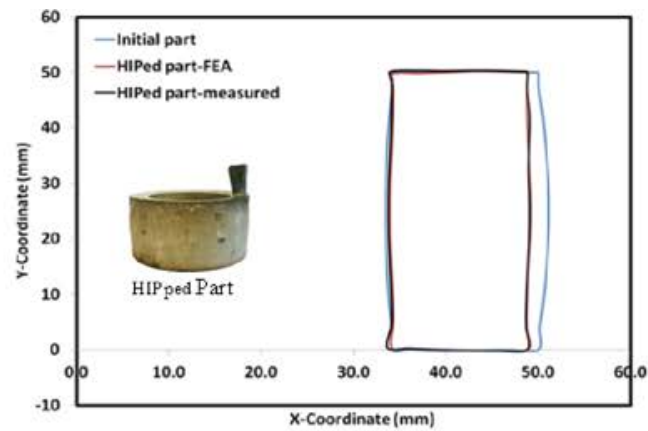

(d)
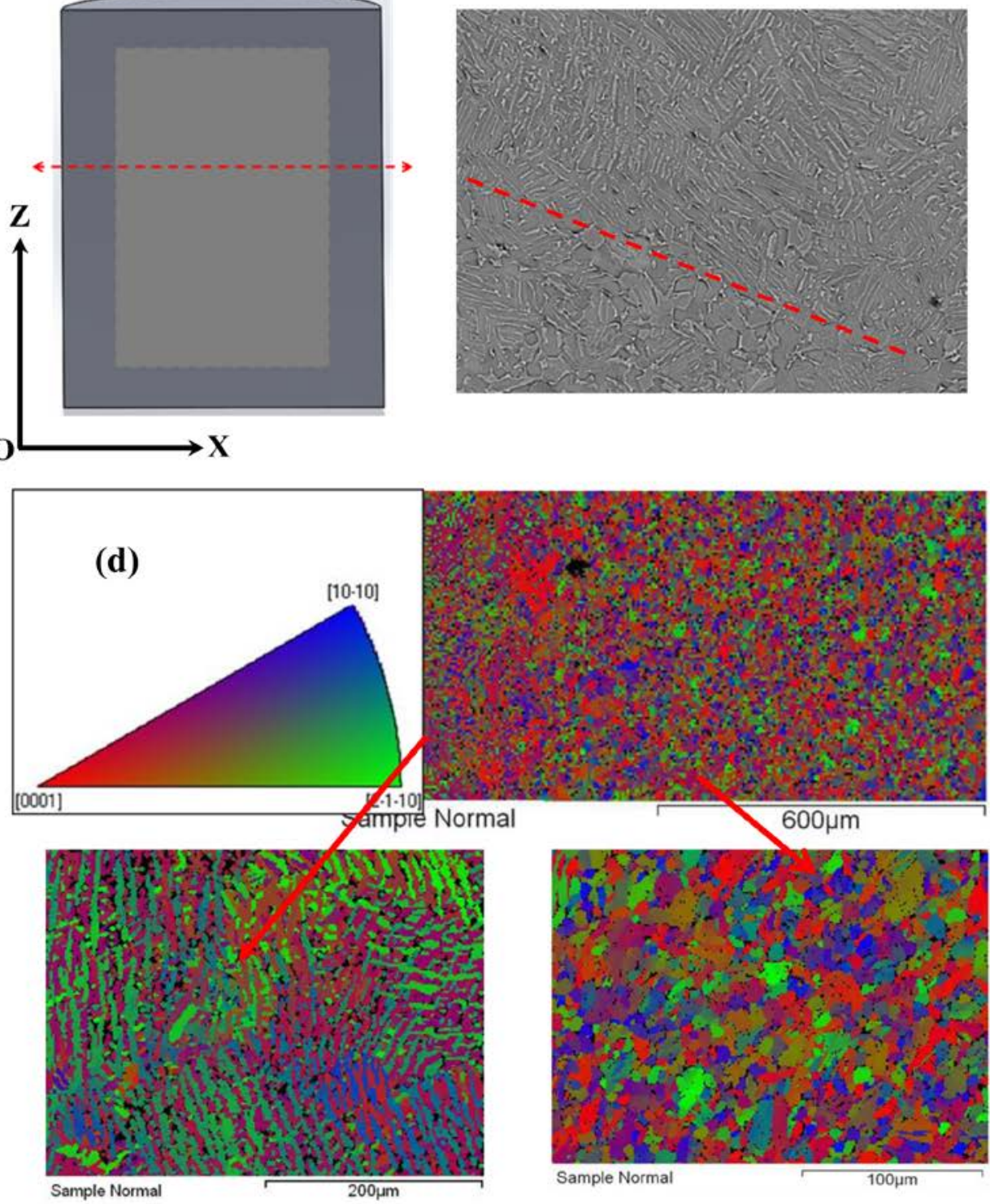

Figure 3: (a,b) A comparison between geometry obtained from the FE simulation and the experimental measurement; (c) microstructure of the interface, (d) EBSD micrographs showing microstructure at interface between SLMed+HIPed shell and HIPed powder 


\section{Conclusions}

A novel approach to improve SLM productivity by combining it with HIP is developed to further innovate the advanced manufacturing field. The possibility of the hybrid SLS/HIP supported by FEA simulation as a net shape manufacturing process for fabrication of high performance parts has been demonstrated. FE models based on pure plasticity theory of porous metal have been used to simulate HIPping of Ti-6Al-4V powder. The computational model used in this research can be extended to improve the design and fabrication of complex shaped parts made from different materials. Experimental analysis has been carried out to validate the FE model, study the effect of the hybrid SLM/HIP process on the microstructure and to evaluate the time dependent deformation of Ti-6Al-4V powder and capsule during HIPping. The plastic collapse model of porous metal is successfully used for shape prediction. The microstructure reveals good bonding between the SLM-built shell and the surrounding consolidated powders after being HIPed. In addition, SLMed+HIPed shells tend to show coarse columnar grain structure and $\alpha$ lamellar structure whereas the HIPed powder show much finer randomly oriented grains and $\alpha$ laths. These two microstructures are believed to show significant influence on the developed parts deformation and mechanical properties.

\section{Acknowledgments}

The work shown in this paper is part of an AMAZE project (Additive Manufacturing Aiming towards Zero Waste and Efficient Production of High-Tech Metal Products) and was financially sponsored by the Seventh European Frame Programme (FP7), Grant No. NMPSE-2012-0313781. It was also supported by supported by the EPSRC grant (EP/M507672/1). 


\section{References}

Abouaf, M. 1985. Modelisation de la compaction de poudres metalliques frittees. $\mathrm{PhD}$, Universite Scientifique et Medical de Grenoble

Abouaf, M., Bauduin, M. \& Raisson, M. 1982. Prediction of the deformation during the production of near-net-shape superalloy parts by hot isostatic pressing. 2nd International Conf. on Isostatic Pressing. Stratford-upon Avon, England.

Abouaf, M., Chenot, J. L., Raisson, G. \& Bauduin, P. 1988. Finite element simulation of hot isostatic pressing of metal powders. International Journal for Numerical Methods in Engineering, 25, 191-212.

Buchbinder, D., Schleifenbaum, H., Heidrich, S., Meiners, W. \& Bultmann, J. High power Selective Laser Melting (HP SLM) of aluminum parts. 6th International WLT Conference on Lasers in Manufacturing, LiM, May 23, 2011 - May 26, 2011, 2011 Munich, Germany. Elsevier, 271-278.

Cassenti, B. 1980. The manufacture of disks by the Hot Isostatic Pressing process. 16th Joint Propulsion Conference. American Institute of Aeronautics and Astronautics.

Chantarapanich, N., Laohaprapanon, A., Wisutmethangoon, S., Jiamwatthanachai, P., Chalermkarnnon, P., Sucharitpwatskul, S., Puttawibul, P. \& Sitthiseripratip, K. 2014. Fabrication of three-dimensional honeycomb structure for aeronautical applications using selective laser melting: A preliminary investigation. Rapid Prototyping Journal, 20, 551-558.

Das, S., Wohlert, M., Beaman, J. J. \& Bourell, D. L. 1999. Processing of titanium net shapes by SLS/HIP. Materials \& Design, 20, 115-121.

Dong, S., Jiang, D., Tan, S. \& Guo, J. 1996. Hot isostatic pressing and post-hot isostatic pressing of SiC- $\beta$-sialon composites. Materials Letters, 29, 259-263.

Gillia, O., Boireau, B., Boudot, C., Cottin, A., Bucci, P., Vidotto, F., Leibold, J. M. \& Lorenzetto, P. 2007. Modelling and computer simulation for the manufacture by powder HIPing of blanket shield components for ITER. Fusion Engineering and Design, 82, 2001-2007.

Häggblad, H. Å. \& Li, W. B. 1995. A micro mechanical based constitutive model for finite element simulation of hot isostatic pressing of powder. Computer Methods in Applied Mechanics and Engineering, 128, 191-198.

Hauser, C., Sutcliffe, C., Egan, M. \& Fox, P. Spiral growth manufacturing (SGM) - A continuous additive manufacturing technology for processing metal powder by selective laser melting. 16th Solid Freeform Fabrication Symposium, SFF 2005, August 1, 2005 - August 3, 2005, 2005 Austin, TX, United states. University of Texas at Austin (freeform), 1-12.

Jinka, A. G. K. \& Lewis, R. W. 1994. Finite element simulation of hot isostatic pressing of metal powders. Computer Methods in Applied Mechanics and Engineering, 114, 249272.

Khoei, A. R., Molaeinia, Z. \& Keshavarz, S. 2013. Modeling of hot isostatic pressing of metal powder with temperature-dependent cap plasticity model. International Journal of Material Forming, 6, 363-376.

Khor, K. A. \& Gu, Y. W. 1998. Hot isostatic pressing of plasma sprayed yttria-stabilized zirconia. Materials Letters, 34, 263-268.

Li, S., Hassanin, H., Attallah, M. M., Adkins, N. J. E. \& Essa, K. 2016. The development of TiNi-based negative Poisson's ratio structure using selective laser melting. Acta Materialia, 105, 75-83. 
Ma, J., Qin, M., Zhang, L., Tian, L., Ding, X. \& Qu, X. 2014. Improvements in magnetic performance and sintered density of metal injection-molded soft magnetic alloy by hot isostatic pressing. Materials Letters, 125, 227-230.

Mumtaz, K. \& Hopkinson, N. 2009. Top surface and side roughness of Inconel 625 parts processed using selective laser melting. Rapid Prototyping Journal, 15, 96-103.

Mumtaz, K. \& Hopkinson, N. 2010. Selective laser melting of Inconel 625 using pulse shaping. Rapid Prototyping Journal, 16, 248-257.

Qiu, C., Adkins, N. J. E. \& Attallah, M. M. 2013. Microstructure and tensile properties of selectively laser-melted and of HIPed laser-melted Ti-6Al-4V. Materials Science and Engineering A, 578, 230-239.

Qiu, C., Yue, S., Adkins, N. J. E., Ward, M., Hassanin, H., Lee, P. D., Withers, P. J. \& Attallah, M. M. 2015. Influence of processing conditions on strut structure and compressive properties of cellular lattice structures fabricated by selective laser melting. Materials Science and Engineering A, 628, 188-197.

Read, N., Wang, W., Essa, K. \& Attallah, M. M. 2015. Selective laser melting of AlSi10Mg alloy: Process optimisation and mechanical properties development. Materials and Design, 65, 417-424.

Shima, S. \& Oyane, M. 1976. Plasticity theory for porous metals. International Journal of Mechanical Sciences, 18, 285-291.

Simhambhatla, S. \& Karunakaran, K. P. 2015. Build strategies for rapid manufacturing of components of varying complexity. Rapid Prototyping Journal, 21, 340-350.

Tvergaard, V. 1981. Influence of voids on shear band instabilities under plane strain conditions. International Journal of Fracture, 17, 389-407.

Wikman, B., Svoboda, A. \& Häggblad, H. A. 2000. A combined material model for numerical simulation of hot isostatic pressing. Computer Methods in Applied Mechanics and Engineering, 189, 901-913.

Wong, M., Tsopanos, S., Sutcliffe, C. J. \& Owen, I. 2007. Selective laser melting of heat transfer devices. Rapid Prototyping Journal, 13, 291-297.

Yuan, W. X., Mei, J., Samarov, V., Seliverstov, D. \& Wu, X. 2007. Computer modelling and tooling design for near net shaped components using hot isostatic pressing. Journal of Materials Processing Technology, 182, 39-49. 